\title{
The Current Obesity Epidemic: Unravelling the Evolutionary Legacy of Adipose Tissue
}

\author{
Carles Zafon ${ }^{*}, 1$ and Rafael Simó ${ }^{2}$ \\ ${ }^{I}$ Endocrinology Division, Hospital Universitari Vall d'Hebron, Universitat Autònoma de Barcelona, Barcelona, Spain \\ ${ }^{2}$ CIBER de Diabetes y Enfermedades Metabólicas Asociadas (CIBERDEM), Instituto de Salut Carlos III (ISCIII), \\ Diabetes and Metabolism Research Unit, Institut de Recerca Hospital Universitari Vall d'Hebron, Universitat \\ Autònoma de Barcelona, Barcelona, Spain
}

\begin{abstract}
The evolution of organisms is shaped by the selective pressures to which they are subject. Selective pressures produce a trade-off between costs and benefits that ultimately influences the fitness of the whole organism. Classically, it has been pointed out that food intake is allocated between its use for physiological functions and its store for future utilization. Moreover, it is accepted that the perfect survivor must be able to eat and store as many calories as possible when food is available as a buffer against periods of scarcity. Thus, during evolution the ability to overeat and store the extra energy in specialized tissues has conferred an advantage. The strategy is known as the thrifty genotype (TG). The primary form in which chemical energy is stored in the body is fat. The aim of this article is to review the participation of adipose tissue in the TG. The role of fat within an evolutionary framework is explored. Moreover, the evolutionary purposes of the different adipose depots are analyzed, suggesting that each depot could have evolved in order to develop different functions. Finally, the contribution of the TG to the current obesity epidemic is questioned.
\end{abstract}

Keywords: Obesity, adipose tissue, evolutionary, reproduction.

\section{INTRODUCTION}

It is broadly accepted that organisms need to be able to stockpile energy as an insurance against harder times. This, in turn suggests that energy metabolism is asymmetric in favouring energy accumulation. The genetic basis of this disequilibrium in fuel balance is defined as the "thrifty genotype" (TG) [1], a theoretical proposition first coined by Neel more than forty years ago [2]. Thus, the TG has been interpreted as a genotype that confers an exceptional efficiency in the intake and/or utilization of food [2]. This has led to the concept of the perfect survivor someone who can eat and store as many calories as possible when food is available as a buffer against periods of scarcity [3]. It has been postulated that this efficient metabolic system for energy accumulation, fixed by the TG, is the basis of the modern obesity epidemic in the context of the current affluent society [4].

Energy can be stored as the carbohydrate glycogen in liver and muscle and as fat, in the form of triglycerides, in adipose tissue. The energy density of glycogen stores is only $1 \mathrm{kcal} / \mathrm{g}$, whereas the energy density of fat stores is $8 \mathrm{kcal} / \mathrm{g}$ [5]. Moreover, the hydrophobic nature of triglycerides permits efficient energy storage without adverse osmotic consequences [6]. This greater efficiency of storage of energy as fat has been crucial to animals for whom mobility plays an important role [7]. Thus, the primary form in which chemical energy is stored in the body is fat. Virtually all

*Address correspondence to this author at the Hospital Universitari Vall d'Hebron, Passeig Vall d'Hebron 119-129, 08035 Barcelona, Spain; Tel: 0034 932746238; Fax: 0034 932746238; E-mail: 26276czl@comb.cat animal species have found a way to store excess energy in the form of fat [8]. In humans, it has been estimated that healthy young men and women have fat energy stores of 88,500 and $132,500 \mathrm{Kcal}$, respectively. If we consider an energy expenditure of $1350 \mathrm{Kcal} / \mathrm{d}$, these would provide sufficient energy for $60-90$ days [9].

On the other hand, evolutionary biology tells us that natural selection favours the optimal allocation of energy. An organism allocates energy among somatic growth, fertility, and maintenance/survival at each stage of life [10]. Thus, it is mandatory to question how energy resources are allocated among these three principal features. Taking into account that resources are finite, organisms are subjected to a strict fuel budget. This constraint generates unavoidable trade-offs. A trade-off occurs when an increase in fitness due to a change in one trait is opposed by a decrease in fitness due to a concomitant change in a second trait [11]. It must be borne in mind that the word "fitness" (or "Darwinian fitness") refers to the ability of the individuals to leave descendents [12]. In addition, traits must be considered in the context of their contribution to the overall fitness of the organism, not atomized and studied in isolation [13]. Finally, the optimal combination of trait values will vary with environmental conditions [11]. In this context, it is necessary to analyse whether the assumption that the "consumption and storage as many calories as possible" strategy is in accordance with an optimisation model and, moreover, whether this evolved trait is the basis of the current obesity epidemic.

Based on a review of existing data the present article explores the role of adipose tissue in an evolutionary framework. We question the contribution of the TG to the 
current obesity epidemic. In addition, the evolutionary purposes of the different adipose depots have been highlighted.

\section{STORING IS NEITHER EASY NOR FREE}

First of all, stored energy implies an intake food which is in excess of current necessities and such excess food intake carries many potential risks and has a significant cost. There exist multiple theoretical models that try to analyze the myriad of concepts concerned in the so-called "optimal foraging theory". For example, a trade-off between increasing food intake and the increasing risk of predation due to prolonging the time spent searching for food has been recognized. In this regard, the foraging theory has established that the foraging cost must be attributable to several factors such as predation risk, parasitic infection, cost of energy expenditure, cost of respiration, free radical damage, ingestion of toxins, production of toxins by gut bacteria, cost of resource storage and excessive growth [14]. Yearsley et al. [15] compared the effects of cost per unit time spent foraging against the cost per unit food consumed and, in contrast to what might have been expected, they found that the optimal food intake over an animal's lifetime was not maximal. It has been pointed out that increased environmental costs of food generate decreased consumption and, as a result, decreased fat storage [16]. Moreover, it has been shown that the foraging cost of the mother reduces her fitness [17]. Hence, it is a mistake to think that food intake is wholly beneficial and should be maximized as far as physical constraints allow [14]. Furthermore, fat storage entails a cost and adipose tissue has a weight that has to be carried. It has been estimated that specific fat storage contents are over 10 $\mathrm{kg}$ in men and $15 \mathrm{~kg}$ in women [9]. Diaz et al. [18] showed that a weight gain of $10.4 \%$ in young men implied an increase in the energy cost of weight-bearing activity of $11.4 \%$.

In summary, evolutionary biology tells us that living beings do not intake as many calories as possible; rather they balance the benefits of resource intake against the possible cost.

\section{STORING, FOR WHAT?}

The main argument for the existence of a TG is that the promotion of energy depots confers an advantage regarding chances of survival. However, evolutionary success depends on reproductive success, which includes more than just survival [19]. It is accepted that the optimization of reproductive effort is the cornerstone of successful life history strategies. Ellison [20] has pointed out that necessary constraints on the allocation of resources generate unavoidable trade-offs between investment in self and investment in offspring. Accordingly, fat stores and reproduction must be intimately linked. In addition, an effective fat storing strategy should improve fitness. In this regard, in order to accept that TG is an adaptive trait it is necessary to prove that energy storage should be adapted to reproductive status. In other words, the mechanisms that control energy balance must be integrated with those that control reproduction [21]. A paradigm of this condition is the fact that some animals have seasonal patterns of energy storage to maximize the allocation of energy to reproduction [22].
In men it is difficult to limit the different reproductive stages clearly, but in women the three periods (pre-reproductive, reproductive and post-reproductive) are perfectly delimited. Moreover, there is no doubt that women have higher costs of reproduction than men because of pregnancy, childbirth and lactation. In a recent report, Penn and Smith [23] examined the fitness cost of reproduction for husbands versus wives in an historical population. The authors found that this cost is clearly greater for mothers than fathers in terms of parental longevity.

Arking [24] has calculated that the energy cost necessary to carry a human from conception to caloric self-sufficiency is approximately $12.6 \times 10^{6} \mathrm{Kcal}$, which represents $25 \%$ of the two parents daily caloric intake for 20 years. More concretely, pregnancy cost has been estimated at around 80 $000 \mathrm{kcal}$ [1]. It might seem that this amount represents an impressive expenditure. However, there are compensatory strategies which minimize the effort, such as prolonged gestation, incomplete maturation at birth, and the possibility of increasing food intake and decreasing physical activity $[25,26]$. As a result, the daily cost of pregnancy is around $240 \mathrm{kcal}$, which represents an increase of only $10 \%$ above non-pregnant needs [25]. In contrast, lactation is the most energetically demanding part of human reproduction. It has been calculated that breastfeeding has a cost of $500-700$ kcal per day, which accounts for an increase of about $25-33$ $\%$ above non-pregnancy requirements $[1,20]$.

In favour of the connection between reproduction and fat storage is the relation between changes in adipose tissue percentage and age. In this regard, it has been fully demonstrated that adipose content does not remain constant throughout life [27].

\section{STORING IN THE PRE-REPRODUCTIVE STAGE}

Although most mammals do not begin to deposit white adipose tissue until after birth, human foetal fat deposition starts to be substantial as early as the end of the second trimester [28]. As a result, at birth, fat content averages $15 \%$ of total body weight [29], whereas most other species have less than $2 \%$ [28]. After birth, infants continue accumulating fat. Between 0.5 mo and 3-6 mo of age adipose tissue contents reach $25-30 \%$ of body weight $[29,30]$. Thereafter, the percentage of deposition declines slightly [31], reaching a pre-puberal nadir at 5-7 years of age. It has been calculated that the fat gain in the first half year represents more than 70 $\%$ of the total amount of the current available energy for tissue formation during this period [32]. Furthermore, some authors have found gender differences in this pattern of deposition. Koo et al. [33] reported that female infants had significantly higher fat (in absolute terms as well in percentage of total body weight) than male infants. Butte et al. [31] described higher values of percentage of fat mass at 6 and 9 month of age in girls. Thereafter, girls continue accumulating fat more rapidly than boys. At 10 years old, females have approximately $2 \mathrm{~kg}(6 \%)$ more fat mass than males [34].

Whether prepuberal body composition is implicated in the timing of puberty is an issue that remains controversial $[35,36]$. However, many authors are of the opinion that it is necessary to achieve a critical fat mass for the initiation of 
puberty. At this stage, the main components of body composition all increase, but considerable sexual dimorphism exists [37]. Males gain greater amounts of fat free mass, and females acquire more fat mass [38]. Hence, during adolescence, girls gain absolute fat mass at an average annual rate of $1.14 \mathrm{~kg}$, whereas boys maintain a relatively fixed absolute fat mass [34].

\section{STORING IN THE REPRODUCTIVE STAGE}

Body fat depots are greater in adult human females than in other primates and mammals. Adjusting for height, women have on average $34 \%$ more body fat than men. This sexual dimorphism has been related to the reproductive effort. There is no doubt that reproduction is more energetically expensive for women than it is for men. As we have seen earlier, pregnancy has a cost of $240 \mathrm{kcal}$ per day, which represents an increase of $10 \%$ above non-pregnant needs [25]. However, it has been well documented that rather than mobilizing fat stores to provide the energy required, women deposit a net quantity of fat during gestation [26]. Fat begins to accumulate around 6 weeks after conception [39]. During the second trimester one half of the weight gained is fat [40]. Finally, during the last trimester gravides do not deposit any additional adiposity $[25,26]$. Piers et al. [41] determined that from 12 weeks gestation to term women gain $3,1 \mathrm{~kg}$ of adipose tissue. Van Raaij et al. [42] quantified a gain in maternal fat around $2 \mathrm{~kg}$, the same amount calculated by Durnin et al. [43]. Finally, Kopp-Hoolihan et al. [40] reported that women deposited $4.1 \mathrm{~kg}$ of body fat by 36 weeks of gestation. Interestingly, this pattern of fuel accretion was also found in undernourished women $[26,44]$.

\section{STORING IN THE POST-REPRODUCTIVE STAGE}

The ageing process involves several physiological modifications and, among them, a significant change in body composition. It has been shown that senescence is accompanied by a loss of lean body mass and an increase in fat mass. During the last 50 years many authors have attempted to quantify the amount of fat deposited during ageing. For example, Hughes et al. [45] reported that fat mass increases, on average, by $7.5 \%$ per decade. Other authors determined fat content changes by comparing groups at different ages [46-48].

In women, the loss of reproductive capacity enhances these modifications. Menopause transition results in an abrupt body fat deposition [49].

\section{WHERE TO STORE?}

Adipose tissue is not a single homogeneous compartment, but rather a set of tissue-specific regional depots. Total body fat can be divided into two main measurable components, subcutaneous (SF) and internal. Moreover, the internal component is divided into visceral and nonvisceral components [50]. Theoretically, visceral fat (VF) comprises adipose tissue distributed in the three body cavities: intrathoracic, intra-abdominal and intrapelvic [50]. However, many authors refer to VF as synonymous with abdominal fat.
Differences in gene expression and in metabolic properties have been described between SF and VF [51]. Many experimental studies have demonstrated that gene expression profiles of preadipocytes as well as adipocytes from both depots are distinct [52]. For instance, Atzmon et al. [53] observed in rats that $17.9 \%$ of fat tissue expressed genes showed a two-fold or higher difference in their expression between the two compartments. Gesta et al. [54] quantified 197 genes differently expressed in adipocytes from SF and VF in mice. More recently, Perez-Perez et al. [55] have reported 43 proteins whose expression is different in the two depots in humans. Kloting et al. [56] have found significant differences in miRNA between omental and subcutaneous fat depots. miRNA are small non-coding RNA that play an important role in adipocyte differentiation. In agreement with all this evidence, Hishikawa et al. [57] suggested that fat accumulation in each adipose tissue is genetically controlled by species-specific regulatory mechanisms. On the other hand, differences are also apparent in adipocyte anatomy. Thus, SF cells are larger than VF cells [58,59]. In addition, both depots have a different pattern of adipokine release. For example, secretion of adiponectin is not regulated by SF but rather by VF [60-62]. By contrast, leptin levels are determined mainly by the SF compartment [6264]. Similar differences have been identified in other adipokines [65]. Moreover, there exist major differences in autonomic nervous innervation between both tissues. Kreier et al. [66] demonstrated a somatotopic organization with respect to the selective innervation of SF versus VF by both the sympathetic and parasympathetic nervous system. All these specific features among depots imply, logically, differences in their metabolic functions in relation to their lipogenic and lipolitic activity [58,59].

Current knowledge in the characterization of specific depots suggests differences in their developmental origin. Traditionally, adipose tissue has been considered to have a mesodermal origin. However, several lines of evidence support the notion that different adipose tissues may be derived from distinct precursors [8]. Thus, for example, adipose depots exhibit a different timing of appearance during development. In rodents, white adipose tissue develops mainly after birth, first in the perigonadal and subcutaneous depot, and only later in the omental depot. Billon et al. [67] have postulated that adipocytes in the cephalic region arise from the neural crest, whereas those in the trunk derive from the mesoderm.

The location of adipose tissue shows great variation between species. For many invertebrates the largest store is intra-abdominal. In seals and whales it is subcutaneous and most mammals and birds have both intra-abdominal and subcutaneous stores [8]. Among SF depots there are also regional differences. Some rodents store their fat in the tail, whereas gorillas deposit it in the neck and the upper part of the scull [68].

In humans in the pre-reproductive stage adipose accretion is mainly due to subcutaneous storage. It has been calculated that SF accounts for over $89 \%$ of the total adiposity in newborn infants [69]. Thereafter, men and women differ not only in the amount of fat, but also in the pattern of fat deposition. This difference is already apparent in infancy and childhood [70,71]. Females have greater adipose in thighs 
and buttocks and men have a significant quantity of abdominal fat. Thus, women have larger stores of SF, whereas men are more likely to have VF [72]. Kuk et al. [73] determined that for any given waist circumference fat deposition is significantly higher in men than in women. In addition, the amount of $\mathrm{VF}$ is twice as high in men compared to women. Moreover, women have on average $1.8 \mathrm{~kg}$ more subcutaneous abdominal fat than men for any given waist circumference.

During the reproductive stage women store more SF and this trait is accentuated in pregnancy because the vast majority of the aforementioned fat accumulation in pregnant females is observed in subcutaneous depots. Sidebottom et al. [39] have calculated that from 6 to 35 weeks of pregnancy mean thigh skinfold thickness increases by $30 \%$, subcapsular by $35 \%$ and triceps by $13 \%$, above preconception levels.

It has been pointed out that adipose increase in newborn babies and pregnant woman is perfectly connected [27]. Both energy storage strategies serve to fight against future life-threatening episodes of offspring energy scarcity. Infant and mother fat depositions precede critical transitions in food supply. The critical transition from placental to lactation is preceded by foetal fat accumulation [32]. Deposition in pregnancy is for use during lactation. In this regard, Butte et al. [74] estimated that lactation has a cost of $626 \mathrm{Kcal} / \mathrm{d}$ and that the mobilization of energy from stores accounts for $172 \mathrm{Kcal} / \mathrm{d}$, which represents more than $25 \%$ of the extra breast-feeding needs. Some years ago, Brewer et al. [75] compared fat changes from delivery to 6 months postpartum in lactating and non lactating women. The authors showed a mobilization and a significant reduction in skinfold thickness in breast-feeding mothers. Thus, although nowadays wellnourished lactating women mainly achieve energy balance by eating more [76], in the past an important part of the lactation necessities was obtained from the energy stored during gestation. Finally, fat deposition observed in the first six months of life precedes the critical transition of weaning. It is noteworthy that in all these circumstances energy is saved in subcutaneous fat tissue, both in mother and infant. All these observations suggest that, during evolution, the ability to store the extra energy in SF must have conferred a reproductive advantage. This provides a perfect demonstration of the theoretical reasoning of McNamara and Houston [77]. According to the authors, women maximize either the net amount of energy obtained (self-feeding) or the amount of energy delivered to another animal (childbearing) or they store it (provisioning).

In summary, women are physiologically better adapted to store fat than men, and have higher rates of fat uptake into SF depots than males [19].

In the post-reproductive stage women change their pattern of fat deposition. After menopause, there is a redistribution of fat depots, and post-menopausal women increase their amounts of visceral fat [78].

A scheme of the patterns of energy accumulation is shown in Fig. (1).

\section{HORMONAL REGULATION}

The molecular mechanisms underlying the regulation of gender-specific pattern of adipose tissue distribution remain poorly understood, thought this is likely to be regulated by hormonal factors. It has been extensively demonstrated that estrogens favour deposition of subcutaneous fat. Furthermore, energy metabolism is significantly different in women according to their estrogen status. Approximately $50 \%$ of post absorptive energy needs are supplied from the oxidation of fatty acid (FFA). Nielsen et al. [79] have showed that, in physiological states, women have greater relative FFA

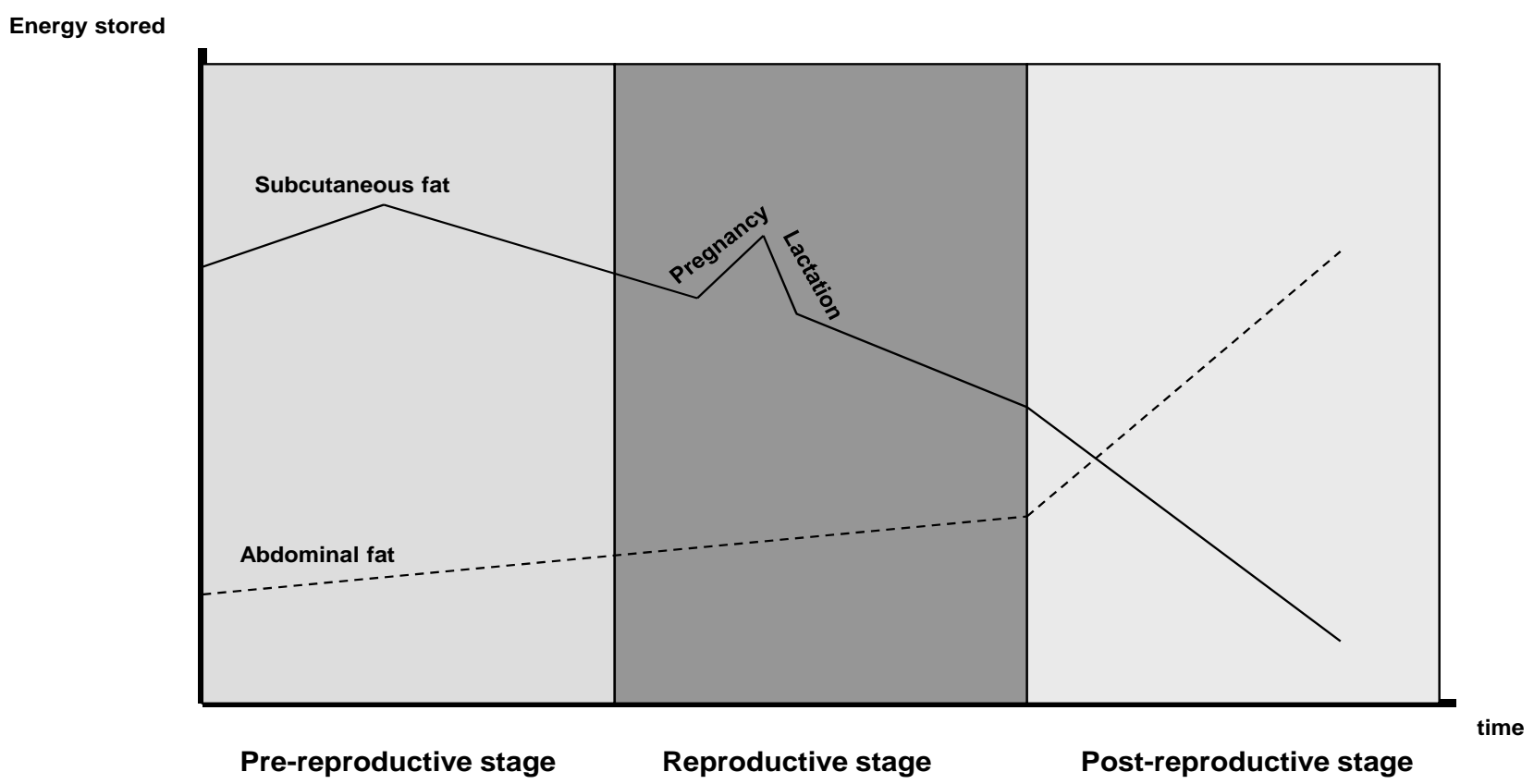

Fig. (1). Divergent patterns of energy accumulation. Energy is deposited in subcutaneous adipose tissue in the reproductive stage, whereas it is predominantly stored in abdominal adipose tissue after that period. 
availability compared with men. In addition, O'Sullivan et al. [71] have reported that postprandial lipid oxidation was different according to estrogen status. Thus, it was lowest in pregnant women (highest estrogen levels), intermediate in nonpregnant premenopausal women, and highest in postmenopausal women (lowest estrogen levels). It has been proposed that this estrogen-dependent reduction in lipid oxidation facilitates efficient fat storage in order to improve reproductive outcome [80].

Specifically, concentrations of estrogens and interaction with their receptors within adipose tissue seem to play an important role in fat accumulation [81]. Formation of estrogens from androgens is catalysed by aromatase cytochrome p450, the product of the CYP19 gene [82]. Aromatase is expressed in several sites, including adipose tissue [83]. In fact, adipose tissue is the major source of estrogen synthesis in men and postmenopausal women. The regulation of aromatase expression occurs, in part, through tissue-specific gene promoters [84]. It has been shown that enzyme expression is related to body fat distribution. Thus, ArKo (aromatase knockout) mice develop marked abdominal adiposity and this phenotype is progressive with age [85]. ErKO (Estrogen receptor knockout) mice exhibit a similar feature. Moreover, fat deposition is reverted after oestrogen administration. In humans, there are marked regional variations in aromatase expression, being higher in SF than in VF. The higher values have been observed in adipose from buttocks and thighs as compared with abdomen [86]. McTernan et al. [87] reported that this pattern of aromatase expression is altered by menopausal status. Thus, postmenopausal women, compared with premenopausal females, showed significant increase in aromatase activity in VF whereas in SF there were no significant differences. Menopausal women have higher visceral fat mass than do premenopausal women for the equivalent percentage of body fat even after adjusting for age [73]. It becomes apparent that changing patterns of fat deposition after menopause is related to with estrogen status. Thus, ovarian hormonedeficient women have significantly higher VF than do premenopausal women [88]. Furthermore, hormone replacement therapy reduces visceral fat storage [89].

Other sex-related molecules have also been linked with fat distribution though the results are less consistent. Thus, for example, it has been shown that circulating androgens are negatively associated with VF, which explains the link between male gender and abdominal fat [90].

\section{OTHER ADIPOSE TISSUE FUNCTIONS}

Adipose tissue is a multifunctional organ, and in addition to the role of lipid storage it has other major and important roles. An evolving body of evidence indicates that several molecules involved in the control of metabolism also play an important function in the regulation of the immune system [91]. There exists a cross-talk between the metabolic and immune systems mediated by a great amount of peptides and other molecules with the mission of integrating energy balance to immune function [92]. In particular, adipose tissue-derived cytokines mediate inflammatory reaction. There is a lot of evidence for the involvement of adipose tissue in both innate and acquired immune response.
Schäffler et al. [93] have proposed adipose tissue as a new member of the immune system. Recent reports suggest that the so-called toll-like receptor (TLR) family is responsible for the initiation of inflammatory response during infection. Specially, TLR-4 participates in the recognition of microbial pathogens and pathogen-associated components. Thus, stimulation of TLR-4 activates proinflammatory pathways and induces cytokine expression (mainly IL-6 and TNF alpha) in a variety of cells [94]. It is known that fatty acids are natural ligands for TLR-4. Several authors have demonstrated the presence of different TLR (TLR-4 principally) in adipocytes and macrophages in mice and in human adipose tissue $[95,96]$. Activation of adipocytes via TLRs results in synthesis of proinflammatory factors. Moreover it has been suggested that TLR could regulate preadipocyte differentiation $[97,98]$. It is interesting to note that mice genetically deficient TLR4 do not become obese with age [99].

Immune response is highly energy demanding. Lipids appear essential in this function as energy suppliers. As Wolowczuk et al. [100] have pointed out, in case of foreign attack energy needs to be delivered very rapidly. At this moment adipose tissue adjacent to lymphoid structures supplies the immune system with fatty acids, which serve as fuel. It is noteworthy that lymph nodes are always embedded with fat depots. A paracrine interaction between adipose and lymphoid cells has been proposed. In this regard, these adipose depots that surround the lymph nodes have been recently characterised. It has been shown that adipocytes in depots that enclose lymph nodes or other rich lymphoid tissue have special properties [101]. It has been demonstrated that perinodal adipocytes do not merely provide energy resources, but also provide immunoregulatory materials [102]. Moreover, they have an intense response to immune stimulus and its fatty-acid contents, as well as they cytokine releasing profile, are also site specific. In particular, $\mathrm{VF}$ is very sensitive to immune stimulants. Omental fat contains large number of the immune active dendritic cells, whereas normal SF contains virtually no amounts of these cells [103]. As a consequence, activated immune cells recruit adipose tissue and enlarge node-containing depots, of which the mesenteric is the largest and most active. Furhermore, Mattacks and Pond [104] have reported that adipocytes specialized to interact locally with immune cells contribute less than other adipocytes to whole-body lipid supply during fasting. Good examples of the relationship between immune function and fat under pathological conditions are Crohn disease or HIV adipose tissue redistribution syndrome (HARS), in both conditions the aberrant responses of the immune system induce a site-specific development of adipose tissue [105]. In the same way, it has been postulated that repeated or chronic infections could lead to enlarged VF [106].

Hence, among the different adipose depots, visceral fat is specifically related to inflammatory features. It is well established that several proinflammatory adipokines are preferentially expressed in VF. Recently, Sam et al. [107] have examined the relationship between SF and VF and inflammatory markers in subjects with type 2 diabetes. The authors have found that VF was positively related with several markers, whereas SF was not so associated. Beasley et al. [108] have reported that in subjects over 70 years old, 
abdominal visceral adiposity was associated with higher levels of inflammatory markers, and that an increase in SF was related to a lower inflammatory milieu. PoulainGodefroy et al. [109] have also demonstrated that inflammation is increased in visceral fat depots. Ample data suggest that pro inflammatory cytokines induce insulin resistance and play a major role in the etiopathogenesis of metabolic syndrome (see below).

\section{TWO TISSUES, TWO FUNCTIONS}

It has been proposed that fat cells have evolved as guardians of multisystem (immune-metabolic) integrity, enhancing chances of survival [110] and becoming a key organ for the regulation of energy metabolism. That conception does not imply that fat always acts as an energetic reservoir. For example, brown adipose tissue is specialised in energy dissipation as heat during cold and diet-induced thermogenesis. So far, we have seen that there exist, at least, two well differentiated adipose tissues, each of them with their genetic, functional, and evolutionary identity. Ontogenetically, it appears that SF has evolved as the energy depot focussed on reproduction. Its regulation is tightly linked with the fertile cycle through the role of sex hormones. Moreover, we must keep in mind that SF has had the same consideration from the cultural point of view. In antiquity, the female model was represented with a significant layer of subcutaneous fat. This was surely because this energy reserve was considered to confer a reproductive advantage. Furthermore, nowadays SF promotes skin attractiveness and acts as a sexual decoy [110]. In summary, SF could be defined as a depot that manages "reproductive energy". For that reason, it becomes a secondary sexual character [111].

On the other hand, over evolution, organism survival has been highly dependent on resistance to infectious disease, and natural selection has favoured genetic adaptations to improve inflammatory response [112]. Energy resources destined for this purpose are very high. VF has specialized as a fuel depot for the immune system and it is characterised as one of the principal resources of inflammatory cytokines. By adapting to that specific function central adipose tissue deposits are more resistant to mobilization. Thus, there would appear to be little adaptive advantage in storing visceral fat [19]. All these factors account for the definition of VF as a depot that manages "defence energy".

Animals must decide between allocating resources to energy reserves and the immune system. There is a trade-off between the risk of starvation and the risk of infectious disease [113], or, in other words, a trade-off between "reproductive energy" and "defence energy". To minimize this disjunction, we have seen that there are two different patterns of fat deposition that are age-dependent. Energy deposits in SF during the reproductive stage and this profile changes drastically at the end of this period, when VF enhances in post menopausal females as well as in aging males.

\section{OBESITY EPIDEMIC}

Obesity has been recognized as a worldwide public health problem. It has been estimated that more than $30 \%$ of USA adults are obese [114]. Moreover childhood and adolescent obesity has grown at an alarming rate [115]. The obesity epidemic has been attributed to a number of factors, such as a sedentary society, the intake of calorie-dense foods and sleep disturbances. In this regard, it is interesting to remark that a number of epidemiologic studies have found a relationship between sleep duration and BMI [116].

Excess body fat is associated with increased all-cause mortality and increased risk of several medical conditions, including type 2 diabetes, dyslipidemia and hypertension [117]. Moreover, obesity is considered to be an important cardiovascular risk factor. Jonsson et al. [118] showed a linear relationship between BMI and incidence of myocardial infarction. Overweigh has many adverse effects on hemodynamics and cardiovascular structure and functions: it increases the risk of left ventricular hypertrophy, leads to left atrial enlargement, and increases the risk for ventricular arrhythmias [119].

However, obesity does not necessarily imply pathology [120]. There is a wide range of body fat distribution also among obese subjects. Nevertheless, the vast majority of obese subjects are classified as abdominal obese and only increased visceral fat is associated with abnormal metabolic complications [121]. Due to its pro-inflammatory profile, abdominal obesity has been considered a chronic inflammatory disease [118]. It has been suggested that this lowgrade inflammation is responsible for the increased cardiovascular morbidity and mortality associated with the overweight condition [122]. Thus, the low-grade-inflammatory state has been postulated as the link between central obesity and all features associated with metabolic syndrome $[65,123]$. Metabolic syndrome is a cluster of risk factors related to cardiovascular disease including type 2 diabetes, hypertension and dyslipemia [124]. It is noteworthy that it has been postulated that SF protects against the metabolic syndrome [125]. For example, Weber et al. [126] have reported that hamsters submitted to subcutaneous lipectomy develop a metabolic syndrome with a significant increase in VF. Snijder et al. [127] have shown that accumulation of fat in legs (in contrast with accumulation in the trunk) has a protective effect in men in relation to glucose abnormalities. In summary, the anatomical distribution of adipose tissue is a key indicator of metabolic alterations and cardiovascular complications [128]. The malignity of obesity is associated with its abdominal form.

\section{REVISING TG}

Several authors have questioned some of the assumptions of the TG $[19,129,130]$. One of the criticisms involves the incapacity to find genes that carry the TG. Power and Schulkin [19] have proposed that pro-obesity genes have become selectivity invisible trough evolution. Speakman [130] has proposed a model of genetic drift to explain the current obesity epidemic. The author has argued that during evolution of early hominids TG, and consequently obesity, was unfavored selected, because of the risk of predation. Afterwards, the risk was removed by the development of social behavior relaxing the anti-obesity genotype.

An updated evolutionary perspective on the role of adipose tissue is mandatory to understand TG strategy. The main hypothesis of this review is that adipose tissue, the 
great energy manager, has evolved, at least, in two depots, both of them with their specific functions. Natural selection has allocated a part of the fat directly to improving fitness and another part to supplying energy and other components of the defense system.

All the foregoing considerations open new and interesting research areas that can be summarized as follow.

1) The organism perfectly adapted to survival is not that organism that is able to store as many calories as possible, but that organism that optimizes the allocation of energy to improve its fitness. In this regard, fuel partitioning must be adapted to the reproductive stage. As a consequence, there is no unique and generic, but several and specific TGs, each of them acting in a timedependent fashion. Accordingly, the expression of genes involved in TG must be searched for taking into account parameters such as age, gender and fertile status. Furthermore, sex hormone physiology appears to be a crucial feature for understanding energy distribution.

2) Adipose tissue becomes the central site of energy management. It is not a single but a set of different and well coordinated fat depots, each of them with specific functions, and with a characteristic evolutionary pathway.

3) The notion that the current epidemic of obesity and abdominal obesity specifically, is the result of an evolved strategy must be interpreted with caution, because the relation between visceral fat accumulation and fitness is not apparent. The evolutionary meaning of the change from SF to VF in the post-reproductive stage should be explored, as well as the reasons why excess of the consumed fat is now preferably deposited in VF. It is possible that an increase in the abdominal region has not been positively selected, or it may be a response to other natural selection pressures different to the TG strategy [51]. In any case, arguments blaming TG as the guilty party of the current obesity spread appears to be too simplistic. It will be necessary to update our current knowledge about metabolic physiology and to adapt these findings to evolutionary concepts, with the aim to actualizing several currently stagnant propositions.

\section{REFERENCES}

[1] Lev-Ran A. Human obesity: an evolutionary approach to understanding our bulging waistline. Diabetes Metab Res Rev 2001; 17: 347-62

[2] Neel JV. Diabetes mellitus: a "thrifty" genotype rendered detrimental by "progress"? Am J Hum Genet 1962; 14: 353-62.

[3] Levin B. Central regulation of energy homeostasis intelligent design: how to build the perfect survivor. Obesity 2006; 14 (Suppl): 192S-196S

[4] Bellisari A. Evolutionary origins of obesity. Obes Rev 2008; 9: 165-80.

[5] Flatt J. Use and storage of carbohydrate and fat. Am J Clin Nutr 1995; 61 (Suppl): 952S-59S.

[6] Rosenbaum M, Leibel RL, Hirsch J. Obesity. N Engl J Med 1997; 337: 396-407.

[7] Cahill G. Starvation. Trans Am Clin Climatol Assoc 1983; 94: 121.

[8] Gesta S, Tseng Y, Kahn C. Developmental origin of fat: tracking obesity to its source. Cell 2007; 131:242-56.

[9] Norgan NG. The beneficial effects of body fat and adipose tissue in humans. Int J Obes 1997; 21: 738-46.
[10] Chu C, Chien H, Lee R. Explaining the optimality of U-shaped age-specific mortality. Theor Popul Biol 2008; 73: 171-80.

[11] Roff D, Fairbairn D. The evolution of trade-offs: where are we? J Evol Biol 2007; 20: 433-47.

[12] Roff D. Defining fitness in evolutionary models. J Genet 2008; 87: 339-48.

[13] Weder AB, Schork N. Adaptation, allometry, and hypertension. Hypertension 1994; 24: 145-56.

[14] Yearsley J, Kyriazakis I, Gordon IJ, et al. A life history model of somatic damage associated with resource acquisition: damage protection or prevention? J Theor Biol 2005; 235: 305-17.

[15] Yearsley J, Hastings IM, Gordon IJ, Kyriazakis I, Illius AW. A lifetime perspective on foraging and mortality. J Theor Biol 2002; 215: 385-97.

[16] Rowland NE, Vaughan CH, Mathes CM, Miltra A. Feeding behavior, obesity, and neuroeconomics. Physiol Behav 2008; 93: 97-109.

[17] Perrigo G. Breeding and feeding strategies in deer mice and house mice when females are challenged to work for their food. Anim Behav 1987; 35: 1298-316.

[18] Diaz E, Prentice AM, Goldberg GR, Murgatroyd PR, Coward WA. Metabolic response to experimental overfeeding in lean and overweight healthy volunteers. Am J Clin Nutr 1992; 56: 641-55.

[19] Power M, Schulkin J. Sex differences in fat storage, fat metabolism, and the health risks from obesity: possible evolutionary origins. Br J Nutr 2008; 99: 931-40.

[20] Ellison PT. Energetics and reproductive effort. Am J Hum Biol 2003; 15: 342-51.

[21] Schneider J. Energy balance and reproduction. Physiol Behav 2004; 81: 289-317.

[22] Sparling C, Speakman JR, Fedak M. Seasonal variation in the metabolic rate and body composition of female grey seals: fat conservation prior to high-cost reproduction in a capital breder? J Comp Physiol (B) 2006; 176: 505-12.

[23] Penn D, Smith K. Differential fitness costs of reproduction between the sexes. Proc Natl Acad Sci USA 2007; 104: 553-8.

[24] Arking R. Human reproductive costs and the predicted response to dietary restriction. Rejuvenation Res 2007; 10: 261-79.

[25] Dufour DL, Sauther ML. Comparative and evolutionary dimension of the energetics of human pregnancy and lactation. Am J Hum Biol 2002; 14: 584-602.

[26] Kopp-Hoolihan LE, Van Loan MD, Wong WW, King JC. Longitudinal assessment of energy balance in well-nourished pregnant women. Am J Clin Nutr 1999; 69: 697-704.

[27] Zafon C. Oscillations in total body fat content through life: an evolutionary perspective. Obes Rev 2007; 8: 525-30.

[28] Wells CK. The evolution of human fatness and susceptibility to obesity: an ethological approach. Biol Rev Camb Philos Soc 2006; 81: $1-23$

[29] Schmelzle HR, Fusch C. Body fat in neonates and young infants: validation of skinfold thickness versus dual-energy X-ray absorptiometry. Am J Clin Nutr 2002; 76: 1096-100.

[30] Fomon SJ, Nelson SE. Body composition of the male and female reference infants. Annu Rev Nutr 2002; 22: 1-17.

[31] Butte NF, Hopkinson JM, Wong WW, O'Brian Smith E, Ellis KJ Body composition during the first 2 years of life: an updated reference. Pediatr Res 2000; 47: 578-85

[32] Kuzawa CW. Adipose tissue in human infancy and childhood: an evolutionary perspective. Am J Phys Anthropol 1998; Suppl 27: 177-209.

[33] Koo WWK, Walters JC, Hockman EM. Body composition in human infants at birth and postnatally. J Nutr 2000; 130: 2188-94.

[34] Veldhuis JD, Roemmich JN, Richmond EJ, et al. Endocrine control of body composition in infancy, childhood, and puberty. Endocr Rev 2005; 26: 114-46.

[35] Buyken A, Karaolis-Danckert N, Remer T. Association of prepubertal body composition in healthy girls and boys with the timing of early and late pubertal markers. Am J Clin Nutr 2009; 89: 221-30.

[36] Sherar L, Baxter-Jones A, Mirwald R. The relationship between body composition and onset of menarche. Ann Hum Biol 2007; 34: 673-7.

[37] Siervogel R, Demerath E, Schubert C, et al. Puberty and body composition. Horm Res 2003; 60 (Suppl 1): 36-45.

[38] Loomba-Albrecht L, Styne D. Effect of puberty on body composition. Curr Opin Endocrinol Diabetes Obes 2009; 16: 10-5. 
[39] Sidebottom AC, Brown JE, Jacobs DR. Pregancy-related changes in body fat. Eur J Obstet Gynecol Reprod Biol 2001; 94: 216-23.

[40] Kopp-Hoolihan LE, Van Loan MD, Wong WW, King JC. Fat mass deposition during pregnancy using a four-component model. J Appl Physiol 1999; 87: 196-202.

[41] Piers L, Diggavi S, Thangam S, van Raaij J, Shetty P, Hautvast J. Changes in energy expenditure, anthropometry, and energy intake during the course of pregnancy and lactation in well-nourished Indian women. Am J Clin Nutr 1995; 61: 501-13.

[42] van Raaij J, Schonk C, Vermaat-Miedema S, Peek M, Hautvast J. Body fat mass and basal metabolic rate in Dutch women before, during, and after pregnancy: a reappraisal of energy cost of pregnancy. Am J Clin Nutr 1989; 49: 765-72.

[43] Durnin J, McKillop F, Grant S, Fitzgerald G. Energy requirements of pregnancy in Scotland. Lancet 1987; 2: 897-900.

[44] Thongprasert K, Tanphaichitre V, Valysevi A, Kittigool J, Durnin J. Energy requirements of pregnancy in rural Thailand. Lancet 1987; 2: 1010-2.

[45] Hughes VA, Frontera WR, Roubenoff R, Evans WJ, Fiatarone Singh MA. Longitudinal changes in body composition in older men and women: role of body weight change and physical activity. Am J Clin Nutr 2002; 76: 473-81.

[46] Bemben MG, Massey BH, Bemben DA, Boileau RA, Misner JE. Age-related variability in body composition methods for assessment of percent fat and fat-free mass in men aged 20-74 years. Age Aging 1998; 27: 147-53.

[47] Piers LS, Soares MJ, McCormack LM, O'Dea K. Is there evidence for an age-related reduction in metabolic rate? J Appl Physiol 1998; 85: 2196-204.

[48] Shimokata H, Tobin JD, Muller DC, Elahi D, Coon PJ, Andres R. Studies in the distribution of body fat: I. Effects of age, sex, and obesity. J Gerontol 1989; 44: M66-M73.

[49] Genazzani AR, Gambacciani M. Effect of climacteric transition and hormone replacement therapy on body weight and body fat distribution. Gynecol Endocrinol 2006; 22: 145-50.

[50] Shen W, Wang Z, Punyanita M, et al. Adipose tissue quantification by imaging methods: a proposed classification. Obes Rev 2003; 11 : $5-16$.

[51] Zafon C. Fat and aging: a tale of two tissues. Curr Aging Sci 2009; 2: 83-94.

[52] Vidal H. Gene expression in visceral and subcutaneous adipose tissues. Ann Med 2001; 33: 547-55.

[53] Atzmon G, Yang XM, Muzumdar R, Ma XH, Gabriely I, Barzilai N. Differential gene expression between visceral and subcutaneous fat depots. Horm Metab Res 2002; 34: 622-8.

[54] Gesta S, Blüher M, Yamamoto Y, et al. Evidence for a role of developmental genes in the origin of obesity and body fat distribution. Proc Natl Acad Sci USA 2006; 103: 6676-81.

[55] Pérez-Pérez R, Ortega-Delgado F, García-Santos E, et al. Differential proteomics of omental and subcutaneous adipose tissue reflects their unalike biochemical and metabolic properties. J Proteome Res 2009; 8: 1682-93.

[56] Klöting N, Berthold S, Kovacs P, et al. MicroRNA expression in human omental and subcutaneous adipose tissue. PLoS One 2009; 4: e4699.

[57] Hishikawa D, Hong Y, Roh S, et al. Identification of genes expressed differentially in subcutaneous and visceral fat of cattle, pig, and mouse. Physiol Genomics 2005; 21: 343-50.

[58] Reynisdottir S, Dauzats M, Thörne A, Langin D. Comparison of hormone-sensitive lipase activity in visceral and subcutaneous human adipose tissue. J Clin Endocrinol Metab 1997; 82: 4162-6.

[59] Tchernof A, Bélanger C, Morisset A, et al. Regional differences in adipose tissue metabolism in women: minor effect of obesity and body fat distribution. Diabetes 2006; 55: 1353-60.

[60] Cnop M, Havel PJ, Utzschneider KM, et al. Relationship of adiponectin to body fat distribution, insulin sensitivity and plasma lipoproteins: evidence for independent roles of age and sex. Diabetologia 2003; 46: 459-69.

[61] Kim C, Park J, Park J, et al. Comparison of body fat composition and serum adiponectin levels in diabetic obesity and non-diabetic obesity. Obesity 2006; 14: 1164-71.

[62] Park KG, Park KS, Kim HS, et al. Relationship between serum adiponectin and leptin concentrations and body fat distribution. Diabetes Res Clin Pract 2004; 63: 135-42.
[63] Minocci A, Savia G, Lucantoni R, et al. Leptin plasma concentrations are dependent on body fat distribution in obese patients. Int J Obes Relat Metab Disord 2000; 24: 1139-44.

[64] Takahashi M, Funahashi T, Shimomura I, Miyaoka K, Matsuzawa Y. Plasma leptin levels and body fat distribution. Horm Metab Res 1996; 28: 751-2.

[65] Wajchenberg BL, Giannella-Neto D, da Silva MER, Santos RF. Depot-specific hormonal characteristics of subcutaneous and visceral adipose tissue and their relation to the metabolic syndrome. Horm Metab Res 2002; 34: 616-21.

[66] Kreier F, Fliers E, Voshol PJ, et al. Selective parasympathetic innervation of subcutaneous and intra-abdominal fat - functional implications. J Clin Invest 2002; 110: 1243-50.

[67] Billon N, Monteiro M, Dani C. Developmental origin of adipocytes: new insights into a pending question. Biol Cell 2008; 100: 563-75.

[68] Björntorp P. Adipose tissue. eJIFCC 2000; 12: 1-5.

[69] Harrington TA, Thomas EL, Modi N, Frost G, Coutts GA, Bell JD. Fast and reproducible method for the direct quantification of adipose tissue in newborn infants. Lipids 2002; 37: 95-100.

[70] Henche S, Torres R, Pellico L. An evaluation of patterns of change in total and regional body fat mass in healthy Spanish subjects using dual-energy X-ray absortiometry (DXA). Eur J Clin Nutr 2008; 62: 1440-8.

[71] O'Sullivan AJ, Martin A, Brown MA. Efficient fat storage in premenopausal women and in early pregnancy: a role for strogen. $\mathrm{J}$ Clin Endocrinol Metab 2001; 86: 4951-6.

[72] Lemieux C, Prud'homme D, Bouchard C, Tremblay A, Després JP. Sex differences in the relation of visceral adipose tissue accumulation to total body fatness. Am J Clin Nutr 1993; 58: 4637.

[73] Kuk J, Lee S, Heymsfield SB, Ross R. Waist circumference and abdominal adipose tissue distribution: influence of age and sex. Am J Clin Nutr 2005; 81: 1330-4.

[74] Butte N, King J. Energy requirements during pregnancy and lactation. Public Health Nutr 2005; 8: 1010-27.

[75] Brewer M, Bates M, Vannoy L. Postpartum changes in maternal weight and body fat depots in lactating $v s$. nonlactating women. Am J Clin Nutr 1989; 49: 259-65.

[76] van Raaij J, Schonk C, Vermaat-Miedema S, Peek M, Hautvast J. Energy cost of lactation, and energy balances of well-nourished Dutch lactating women: reappraisal of the extra energy requirements of lactation. Am J Clin Nutr 1991; 53: 612-9.

[77] McNamara J, Houston A. Currencies for foraging based on energetic gain. Am Nat 1997; 150: 603-17.

[78] Ley C, Lees B, Stevenson J. Sex- and menopause-associated changes in body-fat distribution. Am J Clin Nutr 1992; 55: 950-4

[79] Nielsen S, Guo Z, Albu JB, Klein S, O'Brien PC, Jensen MD. Energy expenditure, sex, and endogenous fuel availability in humans. J Clin Invest 2003; 111: 981-8.

[80] O'Sullivan AJ. Does oestrogen allow women to store fat more efficiently? A biological advantage for fertility and gestation. Obes Rev 2009; 10: 168-77.

[81] Pallottini V, Bulzomi P, Galluzzo P, Martini C, Marino M. Estrogen regulation of adipose tissue functions: involvement of estrogen receptor isoforms. Infect Disord Drug Targets 2008; 8: 5260.

[82] Conley A, Hinshelwood M. Mammalian aromatases. Reproduction 2001; 121: 685-95.

[83] Zhao Y, Nichols J, Bulun S, Mendelson C, Simpson E. Aromatase P450 gene expression in human adipose tissue. J Biol Chem 1995; 270: 16449-57.

[84] Agarwal V, Ashanullah C, Simpson E, Bulun S. Alternatively spliced transcripts of the aromatase cytochrome P450 (CYP19) gene in adipose tissue of women. J Clin Endocrinol Metab 1997; 82: 70-4.

[85] Murata Y, Robertson K, Jones M, Simpson E. Effects of estrogen deficiency in the male: the ARKO mouse model. Mol Cell Endocrinol 2002; 193: 7-12.

[86] Bulun S, Simpson E. Competitive reverse transcription-polymerase chain reaction analysis indicates that levels of aromatase cytochrome $\mathrm{P} 450$ transcripts in adipose tissue of buttocks, thihs, and abdomen of women increase with advancing age. J Clin Endocrinol Metab 1994; 78: 428-32.

[87] McTernan P, Anderson L, Anwar A, et al. Glucocorticoid regulation of $\mathrm{P} 450$ aromatase activity in human adipose tissue: 
gender and site differences. J Clin Endocrinol Metab 2002; 87: 1327-36.

[88] Tchernof A, Desmeules A, Richard C, et al. Ovarian hormone status and abdominal visceral adipose tissue metabolism. J Clin Endocrinol Metab 2004; 89: 3425-30.

[89] Sumino H, Ichikawa S, Yoshida A, Murakami M, Kanda T, Mizunuma H. Effects of hormone replacement therapy on weight, abdominal fat distribution, and lipid levels in Japanese postmenopausal women. Int J Obes Relat Metab Disord 2003; 27: 1044-51.

[90] Blouin K, Boivin A, Tchernof A. Androgens and body fat distribution. J Steroid Biochem Mol Biol 2008; 108: 272-80.

[91] Matarese G, Leiter E, La Cava A. Leptin in autoimmunity: many questions, some answers. Tissue Antigens 2007; 70: 87-95.

[92] Dixit V. Adipose-immune interactions during obesity and caloric restriction: reciprocal mechanisms regulating immunity and health span. J Leukoc Biol 2008; 84: 882-92.

[93] Schäffler A, Schölmerich J, Salzberger B. Adipose tissue as an immunological organ: Toll-like receptors, C1q/TNFs and CTRPs. Trends Immunol 2007; 28: 393-9.

[94] Gabler N, Spurlock M. Integrating the immune system with the regulation of growth and efficiency. J Anim Sci 2008; 86 (14 Suppl): E64-E74.

[95] Kopp A, Buechler C, Neumeier M, et al. Innate immunity and adipocyte function: ligand-specific activation of multiple toll-like receptors modulates cytokine, adipokine, and chemokine secretion in adipocytes. Obesity 2009; 17: 648-56.

[96] Vitseva O, Tanriverdi K, Tchkonia T, et al. Inducible Toll-like receptor and NF-kappaB regulatory pathway expression in human adipose tissue. Obesity 2008; 16: 932-7.

[97] Poulain-Godefroy O, Froguel P. Preadipocyte response and impairment of differentiation in an inflammatory environment. Biochem Biophys Res Commun 2007; 11: 662-7.

[98] Schäffler A, Gross P, Buettner R, et al. Fatty acid-induced induction of Toll-like receptor-4/nuclear factor-kappaB pathway in adipocytes links nutritional signalling with innate immunity. Immunology 2009; 126: 233-45.

[99] Johnson G, Riggs B, Platt J. A genetic basis for the "Adonis" phenotype of low adiposity and strong bones. FASEB J 2004; 18: 1282-4.

[100] Wolowczuk I, Verwaerde C, Viltart O, et al. Feeding our immune system: impact on metabolism. Clin Develop Immunol 2008; 2008: $1-19$.

[101] Pond C. Paracrine relationships between adipose and lymphoid tissues: implications for the mechanism of HIV-associated adipose redistribution syndrome. Trends Immunol 2003; 24: 13-8.

[102] Knight S. Specialized perinodal fat fuels and fashions immunity. Immunity 2008; 28: 135-8.

[103] Bedford P, Todorovic V, Westcott E, et al. Adipose tissue of human omentum is a major source of dendritic cells, which lose $\mathrm{MCH}$ class II and stimulatory function in Crohn's disease. J Leukoc Biol 2006; 80: 546-54

[104] Mattacks C, Pond C. Interactions of noradrenalin and tumour necrosis factor $\alpha$,interleukin 4 and interleukin 6 in the control of lipolysis from adipocytes around lymph nodes. Cytokine 1999; 11: 334-46.

[105] Pond C. Long-term changes in adipose tissue in human disease. Proc Nutr Soc 2001; 60: 365-74.

[106] Sadler D, Mattacks C, Pond C. Changes in adipocytes and dendritic cells in lymph node containing adipose depots during and after many weeks of mild inflammation. J Anat 2005; 207: 769-81.

[107] Sam S, Haffner S, Davidson M, et al. Relation of abdominal fat depots to systemic markers of inflammation in type 2 diabetes. Diabetes Care 2009; 32: 932-7.
[108] Beasley L, Koster A, Newman A, et al. Inflammation and race and gender differences in computerized tomography-measured adipose depots. Obesity 2009; 17: 1062-9.

[109] Poulain-Godefroy O, Lecoeur C, Pattou F, Frübeck G, Froguel P. Inflammation is associated with a decrease of lipogenic factors in omental fat women. Am J Physiol Regul Integr Comp Physiol 2009; 295: R1-R7.

[110] Lübeck R. What are subcutaneous adipocytes really good for ...? Exp Dermatol 2007; 16: 45-70.

[111] Singh D. Female judgment of male attractiveness and desirability for relationships: role of waist-to-hip ratio and financial status. $J$ Pers Soc Psychol 1995; 69: 1089-101.

[112] Van Bodegon D, May L, Meji H, Westendorp R. Regulation of human life histories: the role of inflammatory host response. Ann NY Acad Sci 2007; 1100: 84-97.

[113] Houston A, McNamara J, Barta Z, Klasing K. The effect of energy reserves and food availability on optimal immune defence. Proc $\mathrm{R}$ Soc B 2007; 274: 2835-42.

[114] Ogden CL, Carroll MD, Curtin LR, McDowell MA, Tabak CJ, Flegal KM. Prevalence of overweight and obesity in the United States, 1999 - 2004. JAMA 2006; 295: 1549-54.

[115] Adair LS. Child and adolescent obesity: epidemiology and developmental perspectives. Physiol Behav 2008; 94: 8-16.

[116] Knutson KL, Spiegel K, Penev $\mathrm{P}$, et al. The metabolic consequences of sleep deprivation. Sleep Med Rev 2007; 11: 16378 .

[117] Bray GA, Laine C, Goldmann D, Wilson JF. Obesity. Ann Int Med 2008; ITC4: 1-16.

[118] Jonsson S, Hedblad B, Engström G, Nilsson P, Berglund G, Janzon L. Influence of obesity on cardiovascular risk. Twenty-three-year follow-up of 22025 men from an urban Swedish population. Int J Obes 2002; 26: 1046-53.

[119] Lavie CJ, Milani RV, Ventura HO. Obesity and cardiovascular disease. Risk factor, paradox, and impact of weigh loss. J Am Coll Cardiol 2009; 53: 1925-32.

[120] Weiss R. Fat distribution and storage: how much, where, and how? Eur J Endocrinol 2007; 157: S39-S45.

[121] Jensen MD. Role of body fat distribution and the metabolic complications of obesity. J Clin Endocrinol Metab 2008; 93: S57S63.

[122] Nathan C. Epidemic inflammation: pondering obesity. Mol Med 2008; $14:$ : 485-92.

[123] Schäffler A, Müller-Ladner U, Schölmerich J, Büchler C. Role of adipose tissue as an inflammatory organ in human diseases. Endocr Rev 2006; 27: 449-67.

[124] Alberti KGM, Zimmet PZ, Shaw J. Metabolic syndrome - a new world-wide definition. A consensus statement from the International Diabetes Federation. Diabet Med 2006; 23: 469-80.

[125] Cherian M, Santoro T. The role of saturation of fat depots in the pathogenesis of insulin resistance. Med Hypotheses 2006; 66: 7638.

[126] Weber R, Buckley M, Fried S, Kral J. Subcutaneous lipectomy causes a metabolic syndrome in hamsters. Am J Physiol Regul Integr Comp Physiol 2000; 279: R936-R943.

[127] Snijder M, Dekker M, Visser M, et al. Trunk fat and leg fat have independent and opposite associations with fasting and postload glucose levels. Diabetes Care 2004; 27: 372-7.

[128] Clement K, Langin D. Regulation of inflammation-related genes in human adipose tissue. J Intern Med 2007; 262: 422-30.

[129] Paradies Y, Montoya M, Fullerton S. Racialized genetics and the study of complex diseases: the thrifty genotype revisited. Perspect Biol Med 2007; 50: 203-27.

[130] Speakman JR. Thrifty genes for obesity, an attractive but flawed idea, and an alternative perspective: the "drifty gene" hypothesis. Int J Obes 2008; 32: 1611-7.

This is an open access article licensed under the terms of the Creative Commons Attribution Non-Commercial License (http://creativecommons.org/licenses/by$\mathrm{nc} / 3.0 /$ ), which permits unrestricted, non-commercial use, distribution and reproduction in any medium, provided the work is properly cited. 